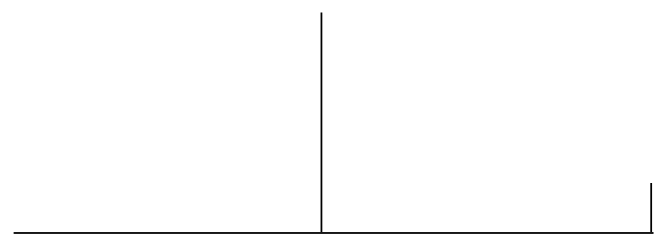

Rev. Latinoam. Psicopat. Fund., São Paulo, v. 15, n. 4, p. 761-765, dezembro 2012

\title{
Editorial
}

\section{Jean Laplanche*}

Jacques André

\begin{abstract}
Era um dia de debate com Daniel Widlöcher, organizado pelo Laboratório de Psicopatologia e Psicanálise que então era dirigido por Jean Laplanche. Widlöcher sugeriu que existiam três desejos, três fontes, que levavam alguém a tornar-se psicanalista: o desejo de cuidar - fonte médica - o desejo de compreender o funcionamento psíquico - fonte psicológica - e o desejo de conhecer o ser humano - fonte filosófica. Widlöcher indicou que o segundo desses desejos, o do psicólogo, orientava seus passos desde o início. Jean Laplanche acrescentou, sem um segundo de hesitação, que era o terceiro, o desejo filosófico, que estava na origem do psicanalista que ele tinha se tornado. Cem anos antes Freud escrevia a Fliess quase a mesma coisa: “... na juventude eu não tinha outra aspiração senão a do saber filosófico e estou agora a ponto de cumpri-la, passando da medicina à psicologia" (Carta de 2 de abril de 1896).
\end{abstract}

* Publicado originalmente em Carnet Psy, maio de 2012.

Tradução de Pedro Henrique Bernardes Rondon. 
Uma noção, mais do que qualquer outra, tanto mais que é quase conclusiva da obra, sublinha essa profunda cumplicidade em Jean Laplanche entre a interrogação filosófica e a experiência psicanalítica, a noção de situação antropológica fundamental - "antropologia", termo de Kant bem antes de ser o de Lévi-Strauss. Se essa formulação é tardia, aquilo que ela engloba trabalha a obra desde seus primeiros passos. O ser humano nasce num estado de Hilflösigkeit, de desamparo - Laplanche traduz - na incapacidade de amparar a si próprio, num estado objetivo de miséria, dependendo totalmente do ambiente humano, inicialmente para sua sobrevivência, em seguida para seu desenvolvimento e sua saúde. Donde o interesse nunca desmentido de Jean Laplanche pelo registro daquilo que Freud chamava de "autoconservação", e que o termo "apego" evoca ainda mais hoje em dia. Certamente, esse território não é exatamente o do psicanalista: essa criança aí não é a dele - o infantil, mais do que a criança, é "a criança" da psicanálise - é mais aquela que o psicólogo observa. O programa genético, as montagens instintivas, aquelas que dirigem a boca do lactente em direção ao mamilo, constituem equipamento que não deixa o recém-nascido sem capacidade de adaptação a suas próprias necessidades - isso não invalida o fato de que a dependência ao ambiente humano, à mãe em primeiro lugar, coloca a criancinha numa passividade quase transcendental, seja qual for, aliás, a atividade que ela possa vir a desenvolver. Destacando a precocidade das competências do recém-nascido, capaz, a partir do terceiro dia, de distinguir as vozes e de se voltar para aquela que "prefere", descrevendo a complexidade das primeiras interações, a psicologia do apego, no entanto, parece seguir uma pista inversa à da passividade. Essa relação espontânea ao objeto - exceto essa abertura imediata da criança para o mundo - situa essa criança tanto mais à mercê daquilo que o mundo lhe dirige. $\mathrm{O}$ bebê de Freud conservava sua própria vida principalmente num modo auto; o modo que as teorias do apego constroem é inter. "Isso que chamam um bebê, não existe ... sozinho", Winnicott já escrevia. Entretanto, para que essa situação antropológica geral e mamífera se torne fundamental, isto é, fundadora do humano nisso que o diferencia do mundo animal mais próximo, ainda que seja preciso acrescentar uma dimensão que a psicologia do apego só pode mesmo ignorar, uma vez que escapa aos seus recursos de observação. Como o adulto - geralmente a mãe - poderia evitar que alguma outra coisa se misturasse aos seus gestos de cuidado, essa parte dele mesmo que ele desconhece e age à revelia dele próprio: o inconsciente? A situação antropológica fundamental é a reunião assimétrica de um adulto dotado de um inconsciente tão sexual quanto irredutível, dispondo de uma alteridade que faz dele um corpo estranho interno, e de um infans inteiramente voltado para a satisfação de suas necessidades elementares (fome, sede, calor, ternura...). Mal-entendido originário, confusão de línguas que Ferenczi des- 
creveu em termos de paixão e ternura. O inconsciente do adulto, da mãe, se mistura, compromete o conjunto das mensagens (não somente linguageiras) dirigidas ao recém-nascido. $\mathrm{O}$ bebê anoréxico sabe bem que para ele seria mais perigoso engolir o leite materno, apesar de sua qualidade nutritiva, do que recusar um alimento humano demais, carregado de angústia, de ódio ou de excitação excessiva. É mais perigoso (psiquicamente) incorporar do que correr o risco de vida da greve de fome.

A teoria de Jean Laplanche se desdobra nesse espaço ao mesmo tempo empírico e originário; ela apoia o primado do outro adulto na constituição do sujeito humano e, no adulto, desse outro que é o inconsciente. Não há inconsciente inato no recém-nascido, as fantasias que são ditas originárias nascem de uma situação tão fundamental quanto incontornável, e não de uma hereditariedade qualquer. Nada há naquilo que constitui a originalidade do psiquismo humano que não seja resultado de uma psicogênese. Não se trata de negar a existência do instinto, inclusive do instinto sexual tal como se manifesta na puberdade. Ao contrário, trata-se de enfatizar que a especificidade do humano nasce da desqualificação instintiva à qual nenhum instinto escapa: fome, sede, agressividade... e, é claro, a sexualidade, algumas vezes tão indiferente ao objetivo do coito, sem falar da reprodução. Mensagem (enigmática), tradução, a posteriori, são alguns dos conceitos-chave do edifício laplancheano. Dentre essas noções, a da sedução ocupa lugar privilegiado, porque conecta a obra de Laplanche ao paradigma da histeria e, é claro, à descoberta freudiana.

Jean Laplanche comentou longamente o abandono de suas neurotica por Freud e, mais do que abandono de uma etiologia da histeria, o abandono do primado do outro, do inconsciente do outro, promessa dessa primeira teoria freudiana. A "queixa" é tanto maior que Freud percebe a fecundidade de um modelo geral da sedução - mais de uma vez ouvi Laplanche "se irritar" com a "concorrência" de Freud, não que este tenha dito tudo, mas porque não há nenhuma pista explorada por seus sucessores que ele não tivesse aberto primeiro. Para ser bem rápido, Freud só deixa de lado o pai perverso da adolescente para descobrir melhor a mãe sedutora do bebê. Essa passagem do pai para a mãe se reforça de um deslocamento: se a mãe doa a seu filho sentimentos oriundos de sua própria vida sexual e amorosa, se ela o trata como "brinquedinho erótico", é à sua revelia, inconscientemente, protegida, portanto, por seu próprio recalcamento, bem diferente do pai perverso das teorias freudianas da neurose. Freud evoca uma mãe genérica, primeira sedutora, sem que ela precise, para isso, fazer nada mais do que cuidar e amar "normalmente" seu filho. O inconsciente da mãe, o seu infantil, faz o restante, que vem embrulhar as trocas, "desadaptá-las" à revelia destas, e sexualizar o conjunto da relação. 
Freud, porém, para por aí, felizmente para Jean Laplanche, que faz teoria geral do psiquismo daquilo que Freud não fez mais do que esboçar. A teoria freudiana do inconsciente fica endógena em larga medida, e não foi a acentuação do inatismo com o surgimento do id que mudou alguma coisa nisso, bem ao contrário.

E quanto à experiência psicanalítica nisso tudo? Foi a vez de Laplanche abrir uma pista cuja exploração deixou aos cuidados dos outros. Procuraríamos em vão a restituição de um momento do tratamento em seus trabalhos escritos. Em compensação, a teoria do tratamento, a teoria da psyché-analyse, quando não é objeto explícito de elaboração, é sempre, pelo menos, o pano de fundo. O volume V das Problématiques: Le baquet, transcendence du transfert (PUF, 1987) desafia sem rodeios o enigma da situação analítica e constitui, acerca da transferência, uma das mais importantes contribuições da psicanálise depois de Freud. A pista progressivamente aberta por Jean Laplanche depois dessa obra até os derradeiros textos consiste em interrogar-se acerca do que liga e articula a experiência da transferência e a situação antropológica fundamental. No fundo - eu aqui mais interpreto Laplanche que o cito - tudo se passa como se o que Freud abandonou em teoria (a sedução), Laplanche descobriu na prática, inventando um dispositivo que é sempre o nosso, apesar de toda a desordem ulterior - incluída aquela que fez Freud passar de uma tópica para outra e que, notavelmente, não acarretou nenhum rearranjo da situação prática. A assimetria do dispositivo analítico decalca a da situação antropológica fundamental, reúne de maneira semelhante o adulto e o infans, e se submete ao primado do outro - do qual ninguém escapa, é o que contratransferência quer dizer.

Desenvolver a fecundidade de tal hipótese, colocá-la à prova, supõe que seja confrontada à realidade das situações clínicas, o que o próprio Jean Laplanche não empreendeu. Dentre as múltiplas questões, há especialmente aquela do encontro entre um dispositivo que nasce e se inventa em contato com a histeria, com formas psicopatológicas que estão muito distantes dela. O que dizer, por exemplo, desses pacientes para os quais a psicanálise não foi inventada - tudo o que fica englobado no registro borderline? $\mathrm{O}$ fato de que é frequente que, de maneira mais impressionante do que os neuróticos, eles possam se beneficiar da dinâmica do tratamento, não cessa de questionar.

A hora não é para o desdobramento dessas questões. Algumas semanas após a morte de Jean Laplanche, o momento é antes de tomar a medida da força da obra dele. Diferentemente de todos esses, psicanalistas, que prudentemente se refugiaram no segredo ou no inatingível, Jean Laplanche o tempo todo corre o risco de ser compreendido e, portanto, de ser discutido, debatido - outra forma de fidelidade a Freud. As continuidades entre a obra de Laplanche e a de Lacan, 
o Lacan ao qual devemos a fórmula "o desejo é o desejo do Outro", essas continuidades são determináveis. Porém, Jean Laplanche mais de uma vez observou e lamentou que alguma coisa no estilo de Lacan se recusava ao trabalho, recusava a se deixar trabalhar, desarrumar.

Martial Guéroult, um dos meus antigos mestres de filosofia, dizia que um bom livro é aquele que ainda lemos cinquenta anos após seu lançamento. Será que Laplanche ainda será lido daqui a cinquenta anos? Aposto que sim, especialmente porque a obra é prenhe de questões que ela própria apenas apresentou, obra em aberto que podemos descobrir sem que sejamos condenados nem a aderir a ela nem a rejeitá-la. Uma pequena volta ao mundo da psicanálise hoje em dia permite rapidamente constatar que a discussão já começou.

\section{JACQUES ANDRÉ}

Membro da Associação Psicanalítica da França - APF (Paris, França), filiada à International Psychoanalytical Association (IPA); Professor de Psicopatologia da Universidade de Paris 7 - Denis Diderot (Paris, França); Diretor do Centre d'Etudes en Psychopathologie - CEPP (Paris,França). 